\title{
Pilha de combustível
}

\author{
A N A B E L V IEGAS*, MARIA C LARA MAGA L A E S ${ }^{* *}$ M A R I ISA B L FERREIRA ***
}

\section{Sugestões para a actividade}

Há diversos aspectos relacionados com a electroquímica que se podem explorar, tais como: a constatação e entendimento da electrólise, nomeadamente as reacções de oxidação-redução; a cinética das reacções químicas; e questões de ácido-base e precipitação.

A ficha de trabalho experimental (Pilha a água salgada!) encontra-se na parte dos alunos. Começa com a questão: «Como criar um dispositivo que utiliza água salgada para transformar energia química em energia eléctrica?»

A partir das respostas apresentadas pelos alunos, o professor poderá ir facultando pistas indicando o material disponível.

\section{Introdução}

Enquadramento geral (socioeconómico a nível mundial) das necessidades mundiais e do desenvolvimento sustentado

O estudo da pilha de combustível é importante na medida em que contribui para uma evolução na questão energética. Poderá ajudar na travagem ao aumento do aquecimento global, resultante do consumo desenfreado dos combustíveis fósseis, e também pode ser importante para satisfazer as necessidades dos países em desenvolvimento.

Sabe-se que continuar a utilizar as fontes primárias de energia: carvão e petró- leo não corresponde à exigência de um desenvolvimento "sustentável", uma vez que há uma tomada de consciência, por parte da população em geral, dos danos que provocam, designadamente no que concerne à qualidade do ar e às suas consequências para a saúde pública. Boeker e Grondelle [1] e Baird [2] referem os gases que mais contribuem para o aumento do efeito de estufa, bem como a concentração destes gases na troposfera. 0 dióxido de carbono, o metano e os óxidos de azoto são exemplos relevantes de gases que contribuem para o aumento do efeito de estufa. Elevadas concentrações de monóxido de carbono ingerido pelo ser humano conduzem ao envenenamento da hemoglobina no sangue o que, em situação extrema, provoca a morte por asfixia [3]. Devido à combustão incompleta de combustíveis fósseis são libertadas para a atmosfera dioxinas. Em elevadas concentrações estas poderão causar, entre outros, problemas respiratórios [3].

O consumo excessivo de combustíveis fósseis, especialmente por parte dos países ricos, levou a uma mobilização social em torno de novas soluções para o sector energético. Segundo dados dos peritos do sector energético, dentro de quarenta anos o petróleo deixaria de estar a preços acessíveis, no entanto os investigadores em geologia para o sector petrolífero referem que a crise vai chegar antes desta década. Neste contexto surge o Protocolo de Quioto, em 1998, e nessa altura a Europa comprometeu-se a reduzir em 8\%, em relação ao seu nível de 1990, as emissões de dióxido de carbono no período compreendido entre 2008 e 2012.

O sector dos transportes é apontado como o "mau da fita" do Protocolo de Quioto; com efeito, entre 1980 e 1999 o número de veículos de transporte de mercadorias quintuplicou e foi reforçado o papel do transporte individual, uma vez que este meio proporciona maior mobilidade. É verdade, ainda, que na União Europeia os transportes são responsáveis por $26 \%$ do total de emissões de dióxido de carbono e por $63 \%$ do total de emissões de óxidos de azoto.

A conjuntura energética da era "pósQuioto" transforma as energias sustentáveis e não poluentes num enorme desafio, pelo que o hidrogénio tem potencialidade para mudar radicalmente a cultura ambiental da nossa civilização.

Quando a tecnologia estiver optimizada de modo a que o hidrogénio seja produzido e utilizado adequadamente, ele não se esgotará (a uma escala humana) e estará isento da produção de dióxido de carbono.

O hidrogénio é abundante, mas não existe livremente na superfície da Terra, pelo que terá de ser extraído das suas fontes naturais. Actualmente, cerca de metade do hidrogénio que se produz é extraído do gás natural. Utiliza-se vapor de água para converter o gás natural em hidrogénio comercial. Como o gás

\footnotetext{
* Escola Secundária de Oliveira do Bairro, Rua dos Colégios - Vale do Mouro, 3770-855 Oliveira do Bairro (viegasanabela@hotmail.com)

** Departamento de Química, Universidade de Aveiro, Aveiro

*** Departamento de Física, Universidade do Minho, Braga
} 
natural é constituído essencialmente por metano, através das equações (1) e (2) traduzem-se estas transformações químicas.

Mas o gás natural é um hidrocarboneto e por isso haverá emissão de dióxido de carbono aquando do processo de obtenção do hidrogénio, o que não resolve o problema ambiental da redução das emissões de dióxido de carbono para a atmosfera. Além disso, prevê-se que o pico de consumo do gás natural seja entre 2020 e 2030 para depois diminuir até se extinguir [4].

Pode-se obter hidrogénio por electrólise da água (ver equação 3), recorrendo por exemplo à energia eléctrica obtida a partir de vapor fornecido geotermicamente através da energia produzida por outras fontes de energia renováveis. Este caminho está em progressivo desenvolvimento, existindo já na Dinamarca e na Noruega. Em Portugal também existem várias centrais eólicas produtoras de energia eléctrica. Como exemplo refere-se a que existe em Lamego-ver figura 1.

Nos dias de hoje já se produzem pilhas para uso doméstico que utilizam o hidrogénio como combustível [5]. Futuramente, segundo o Presidente da Fundação sobre Tendências Económicas, Jeremy Rifkin [5]: "na "economia de hidrogénio" até o automóvel será uma central eléctrica com rodas com uma capacidade geradora de $20 \mathrm{kW!».} \mathrm{Uma}$ vez que o automóvel está estacionado umas boas horas, poderá ser ligado à rede da casa, ou à oficina, injectando energia extra na rede. Se apenas um quarto dos condutores usassem os seus automóveis como "centrais eléctricas" para dar energia eléctrica à rede, poderiam ser eliminadas todas as centrais eléctricas de um país [5].

$$
\begin{array}{ll}
\mathrm{CH}_{4}(\mathrm{~g})+\mathrm{H}_{2} \mathrm{O}(\mathrm{g}) \leftrightarrows \mathrm{CO}(\mathrm{g})+3 \mathrm{H}_{2}(\mathrm{~g}) & \Delta \mathrm{rH}^{0}=250,11 \mathrm{~kJ} \mathrm{~mol}^{-1} \\
& \Delta \mathrm{rG}^{0}=150,68 \mathrm{~kJ} \mathrm{~mol}^{-1} \\
\mathrm{CO}(\mathrm{g})+\mathrm{H}_{2} \mathrm{O}(\mathrm{g}) \leftrightarrows \mathrm{CO}_{2}(\mathrm{~g})+\mathrm{H}_{2}(\mathrm{~g}) & \Delta \mathrm{rH}^{0}=-41 \mathrm{~kJ} \mathrm{~mol}^{-1} \\
& \Delta \mathrm{rG} \mathrm{G}^{0}=-20 \mathrm{~kJ} \mathrm{~mol}^{-1} \\
\mathrm{H}_{2} \mathrm{O}(\mathrm{g}) \leftrightarrows 2 \mathrm{H}_{2}(\mathrm{~g})+\mathrm{O}_{2}(\mathrm{~g}) & \Delta \mathrm{rH}^{0}=286 \mathrm{~kJ} \mathrm{~mol}^{-1}
\end{array}
$$

Figura 1 Fotografia de aerogeradores do Parque Eólico da Fonte da Mesa, situado na Serra das Meadas em Lamego.

\section{Objectivos}

- Compreender a pilha de combustívelcomo sistema termodinâmico "limpo" que pode ser utilizada em veículos au-

- Introduzir o estudo da célula de combustível.

- Criar uma célula electroquímica que envolve gases como reagentes.

- Explorar algumas reacções de oxidação-redução.

\section{Pilha a água salgada!}

Neste sistema demonstrativo efectua-se em primeiro lugar uma electrólise e posteriormente a transformação de energia química em eléctrica. Através da demonstração com este sistema procura-se responder ao problema:

- Como criar um dispositivo que utiliza água salgada para transformar energia química em energia eléctrica?

\section{Conceitos "chave"}

Há que fornecer informações científicas aos alunos a fim de poderem interpretar o que sucede quando se executa o 7. ${ }^{\circ}$ passo do procedimento. Ou seja, há transferência de electrões, do eléctrodo negativo da pilha seca para o eléctrodo positivo de cromoníquel. O eléctrodo que produz electrões é designado por ânodo (é o eléctrodo em que ocorre a oxidação) e o eléctrodo que recebe electrões é designado por cátodo (é o eléc- 
trodo em que ocorre a redução). Por conseguinte, do pólo negativo da pilha seca saem electrões que entram no pólo positivo (cátodo) da pilha electrolítica. Estes electrões combinam-se com a água da solução aquosa e forma-se hidrogénio gasoso junto ao cátodo e hidróxido de sódio. Devido à formação da base consegue-se detectar um aumento no valor de $\mathrm{pH}$. No ânodo da célula "artesanal", os iões cloreto presentes em solução libertam electrões e produzem cloro gasoso que é libertado para a atmosfera. Poder-se-ia achar que se iria formar oxigénio gasoso em vez do cloro junto ao ânodo, uma vez que o potencial padrão de oxidação da água é maior do que o da oxidação do ião cloreto (oxidação-redução (4) e (5)). No entanto, no estudo dos processos electrolíticos verifica-se por vezes que a sobretensão necessária para iniciar uma dada reacção é consideravelmente superior ao valor dos potenciais de eléctrodo. Ou seja, a sobretensão, que é a voltagem adicional necessária para provocar a electrólise, para a formação de oxigénio é bastante elevada. Portanto, em condições normais de funcionamento forma-se no ânodo cloro gasoso além do oxigénio gasoso.

O cloro gasoso tem uma cor amarelo-esverdeado, mas a cor da solução observada não se deve a este gás atendendo à sua fraca solubilidade. Provavelmente resulta da complexação dos iões cloreto e hidróxido com os iões metálicos provenientes da oxidação do eléctrodo.

$2 \mathrm{Cl}^{-}(\mathrm{aq}) \rightarrow \mathrm{Cl}_{2}(\mathrm{~g})+2 \mathrm{e}^{-}$

$2 \mathrm{H}_{2} \mathrm{O}(\mathrm{I}) \rightarrow \mathrm{O}_{2}(\mathrm{~g})+4 \mathrm{H}^{+}(\mathrm{aq})+4 \mathrm{e}^{-}$

$E^{0}=-1,36 V$

$\mathrm{Na}^{+}(\mathrm{aq})+\mathrm{e}^{-} \rightarrow \mathrm{Na}(\mathrm{s})$

$E^{0}=-1,229 V$

$2 \mathrm{H}_{2} \mathrm{O}(\mathrm{I})+2 \mathrm{e}^{-} \rightarrow \mathrm{H}_{2}(\mathrm{~g})+2 \mathrm{OH}^{-}(\mathrm{aq})$

$E^{0}=-2,71 V$

$2 \mathrm{H}^{+} \rightarrow \mathrm{H}_{2}(\mathrm{~g})+2 \mathrm{e}$

$E^{0}=-0,83 V$

$E^{0}=0,00 V$

Quando se utiliza água da torneira, em vez de solução aquosa de cloreto de sódio ou água do mar, verifica-se que há formação de bolhas de gás mais lentamente do que na solução aquosa de cloreto de sódio, uma vez que a água da torneira contém iões dissolvidos, mas não é tão concentrada em iões como as outras soluções. Assim, pode-se falar na influência da concentração iónica na velocidade das reacções.

Pode-se esboçar um esquema do circuito eléctrico correspondente ao sistema da demonstração (figura 2).

É sabido que umas pilhas duram mais do que outras, no entanto a pilha seca que se utiliza muito nos laboratórios das escolas básicas e secundárias de Portugal continua a ser a rectangular de $4,5 \mathrm{~V}$ (é constituída por três células de Leclanché associadas em série, gerando cada célula uma diferença de potencial de $1,5 \mathrm{~V}$ ).

Poder-se-ia utilizar em vez de eléctrodos de cromoníquel, eléctrodos de platina pois para além de serem bons condutores eléctricos, proporcionam as superfí- cies necessárias para a decomposição inicial das moléculas em espécies atómicas que antecede a transferência de electrões, ou seja são electrocatalisadores. Também se poderia dopar grafite com qualquer um destes catalisadores referidos, mas esta alternativa não é fácil de praticar nas escolas básicas e secundárias.

Qual o motivo porque à lupa se observa que o eléctrodo junto do qual se forma hidrogénio gasoso é cinzento e o outroestá mais fino e ligeiramente acobreado?

Um dos eléctrodos fica mais fino, uma vez que se dissolve na solução.

Procedendo a uma análise simplista, sem considerar a possibilidade de formação de complexos dos iões metálicos, há que considerar o que se segue, atendendo à formação de cloro junto ao ânodo da pilha electroquímica.

Ao nível microscópico, teoricamente, pode, no cátodo, haver redução de $\mathrm{Na}^{+}$, $\mathrm{H}_{2} \mathrm{O}$ ou $\mathrm{H}^{+}$, uma vez que os potenciais de redução das respectivas equações (ver equações 6 a 8) são menores do

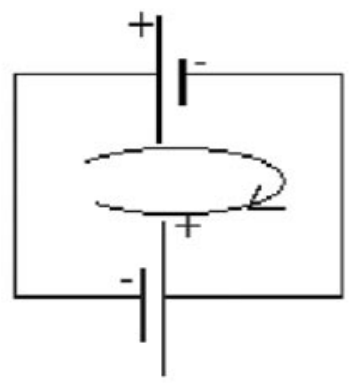

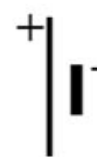

pilha seca

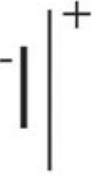

célula electrolítica

sentido real de circulação

de electrões

na electrólise (ou seja sen-

tido real

corrente eléctrica)
Figura 2 Esquema do circuito eléctrico de demonstração para a electrólise. 
que o potencial fornecido pela pilha de Leclanché.

De acordo com a experiência efectuada verificou-se que o pH após a electrólise era 12, pelo que a solução é básica, portanto a concentração de iões $\mathrm{H}^{+}$no final é demasiado baixa. Os potenciais zero e -0,83V implicam que a pressão de hidrogénio seja uma atmosfera e as concentrações de ião hidrogénio e

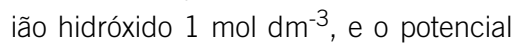
-2,71 V implica que a concentração de ião sódio seja também a concentração padrão, o que não corresponde à realidade da experiência.

Uma vez que se obteve, após a aplicação de uma diferença de potencial, dois eléctrodos diferentes, obteve-se uma pilha. O facto de se formarem dois gases diferentes em cada eléctrodo é um contributo para haver um aumento de potencial.

Quando se desliga a pilha seca do circuito há uma inversão de funções dos eléctrodos. Supostamente o cromoníquel terá comportamento de catalisador, pelo que a velocidade das reacções inversas à electrólise vai aumentar. Ou seja, o hidrogénio gasoso na superfície do eléctrodo que funcionava como cátodo, e que passa a ser ânodo, liberta electrões e protões, como se pode ver em (9).

Os protões flúem na solução aquosa e os electrões pelo circuito externo, portanto no outro eléctrodo, ou seja no cátodo, forma-se ião cloreto (equação 10). Observou-se experimentalmente que a diferença de potencial decaiu imediata-

$$
\begin{array}{ll}
\mathrm{H}_{2}(\mathrm{~g}) \rightarrow 2 \mathrm{H}^{+}(\mathrm{aq})+2 \mathrm{e}^{-} & \mathrm{E}^{0}=0,00 \mathrm{~V} \\
\mathrm{Cl}_{2}(\mathrm{~g})+2 \mathrm{e}^{-} \rightarrow 2 \mathrm{Cl}^{-}(\mathrm{aq}) & \mathrm{E}^{0}=1,36 \mathrm{~V} \\
\mathrm{Cl}_{2}(\mathrm{~g})+\mathrm{H}_{2}(\mathrm{~g}) \rightarrow 2 \mathrm{HCl}(\mathrm{aq}) & \mathrm{E}^{0}=1,36 \mathrm{~V}
\end{array}
$$

Para determinar o rendimento máximo teórico da pilha electrolítica é necessário calcular, nas condições reais de laboratório, a variação de energia de Gibbs da reacção. No entanto, como apenas se pretende perceber a ordem de grandeza do rendimento, calcula-se a variação da energia de Gibbs padrão da reacção (11), $\Delta_{r} G^{0}$, a $25^{\circ} \mathrm{C}$. Para isso recorrese a valores tabelados da variação de energia de Gibbs padrão de formação, $\Delta_{f} G^{0}$, a $25^{\circ} \mathrm{C}$.

$\Delta_{r} G^{0}=2 \Delta_{f} G^{O}(\mathrm{HCl})-\left[\Delta_{f} G^{0}\left(\mathrm{H}_{2}\right)+\Delta_{f} G^{0}\left(\mathrm{Cl}_{2}\right)\right]=$ $=-262,46-0=-262,46 \mathrm{~kJ} \mathrm{~mol}^{-1}$

Também é necessário recorrer a valores de variação de entalpia padrão correspondente.

$$
\begin{aligned}
\Delta_{r} H^{0} & =2 \Delta_{f} H^{0}(H C l)-\left[\Delta_{f} H^{0}\left(H_{2}\right)+\Delta_{f} H^{0}\left(\mathrm{Cl}_{2}\right)\right]= \\
& =-334,32-0=-334,32 \mathrm{~kJ} \mathrm{~mol}^{-1}
\end{aligned}
$$

Logo, o rendimento teórico máximo, em condições padrão e à temperatura de $25^{\circ} \mathrm{C}$ será:

$$
\eta_{\text {máx }}=\Delta_{r} G^{0} / \Delta_{r} H^{0}=0,78
$$

\section{Referências}

1 E. Boeker e R. van Grondelle, Environmental Physics, J. Wiley \& Sons, Chichester, 1995.

2 C. Baird, Environmental Chemistry, 3rd edition, W. H. Freeman and Company, New York, 1997

3 A. Winfield, Environmental Chemistry, Cambridge University Press, New York, 1995.

4 Dossier Especial: Energias Alternativas - A Pilha de Combustível, em http://www.negocios.pt/estatico/automovel2002energias. asp (acedido em Novembro 2002).

5 P. Hoffmann, Tomorrow's Energy - Hidrogen, Fuel Cells, and the Prospects for a Cleaner Planet, The MIT Press: Cambridge, 2001.

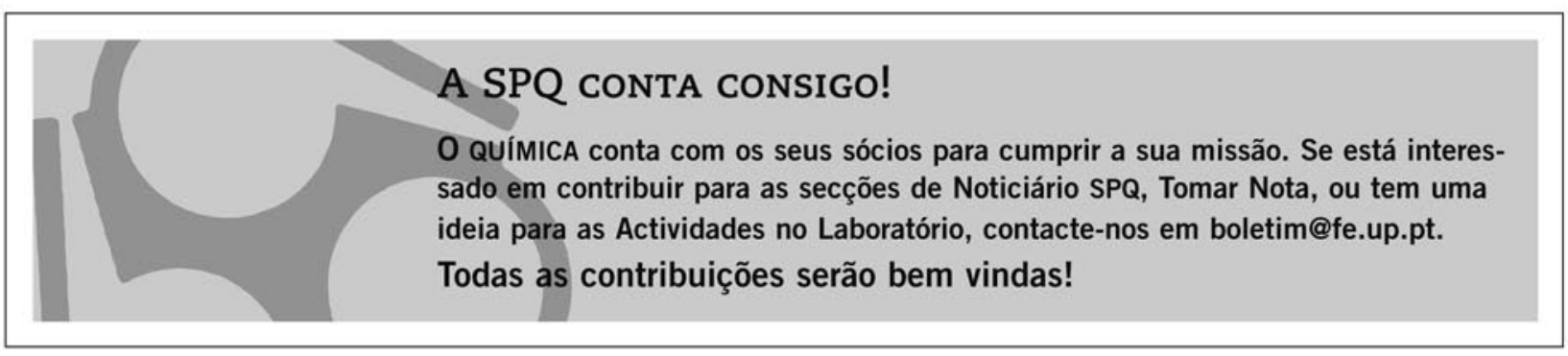

